\title{
Does circumcision change uroflowmetry parameters?
}

\author{
Serpil Sancar ${ }^{1} \oplus$, Elif Altınay Kırlı Egemen²® \\ ${ }^{1}$ Department of Pediatric Surgery, Bursa City Hospital, Bursa, Turkey \\ ${ }^{2}$ Department of Pediatric Urology, Bursa City Hospital, Bursa, Turkey
}

\begin{abstract}
Objectives: The benefits of circumcision, which is one of the most frequently performed surgical procedures, are controversial. In our study, before and after circumcision, uroflowmetry parameters were compared to evaluate the effects of circumcision on voiding.

Methods: Children between the ages of 5-15 years who applied to the outpatient clinic for voluntary circumcision and who did not have underlying diseases and voiding problems were included in the study. Circumcision was performed by specialist in sterile conditions under general anesthesia. Uroflowmetry was evaluated by voiding volume, voiding time, maximum flow rate, average flow rate, shape of the curve. The pre-circumcision and post-circumcision uroflowmetry results were compared statistically.

Results: Fifty patients with a median age of seven years (range: 5-10 years) were included in the study. When uroflow parameters were compared in our study, the maximum flow rate, mean flow rate and the time to maximum flow rate were found significantly different $(p<0.05)$. The plateau pattern was detected in $30 \%$ of patients before circumcision, while in $8 \%$ of patients after circumcision.

Conclusions: Circumcision performed by specialists under sterile conditions has positive effects on uroflow parameters.

Keywords: Male circumcision, uroflowmetry, children
\end{abstract}

$\mathrm{C}$ ircumcision is the surgical removal of the prepuce, either in whole or in part. It is one of the most practiced surgical procedures in the world. There is no standardization regarding the surgical technique. Today, the debate continues with regard to the usefulness of the practice of circumcision. In the literature, there are publications that set forth opposing views about its practice due to the fact that foreskin protects the penis tip with both mechanical and secreted substances and because of its functional importance in orgasm in sexual life due to the presence of many sensory receptors. However, there are also studies showing that the practice of circumcision is beneficial in children who have frequent urinary tract infections and that this practice has a protective role in sexually transmitted diseases such as AIDS [1-3].

As a result, circumcision is a surgical procedure that is very frequently practiced based on religious beliefs, traditional reasons or medical reasons. A series from the year 2010 states that there is no systematic study comparing circumcised men and uncircumcised men [4]. The effect of circumcision on voiding dynamics in children or adults is still an unknown issue.

Uroflowmetry is an easy-to-apply, non-invasive test in which voiding is evaluated. Uroflowmetry can 
be used to assess the effect of circumcision on urine flow. In our study, it was aimed to investigate the effects of circumcision on uroflowmetry parameters.

\section{METHODS}

Upon the approval by the local ethics committee, children between the ages of 5-15 years were enrolled, who applied to the outpatient clinic for voluntary circumcision and who had no underlying disease and voiding problems. There was no phimosis precircumcision. After obtaining consent from their families, uroflowmetry was performed before circumcision. Circumcision was performed under general anesthesia by the surgical circumcision method. In the circumcision, the preputium was removed in a way that approximately $0.5 \mathrm{~cm}$ of preputium remained on the side of the glans, without performing frenulum excision. After excision, the glans-skin flap was repaired with individual sutures with 5/0 Rapid Vicryl. On the first day, closed dressings were made, and the dressing was opened one day later, and povidone-iodine was recommended to be applied twice a day. After one-day hospitalization, oral analgesics and anti-inflammatory medication (Ibuprofen $5 \mathrm{mg} / \mathrm{kg}, 3 \times 1$, daily) were started and the patient was discharged. Bathing was recommended two days later, along with an outpatient visit one week later for incision control. An outpatient visit was recommended one month after circumcision for voiding control, and post-circumcision uroflowmetry was performed at this control.

The uroflowmetry was assessed based on voided volume, flow time, maximum flow rate, avarage flow rate, and the shape of the curve. Voided volume was excluded in children under $50 \mathrm{cc}$ [5]. The expected bladder capacity was calculated as $30+($ age $\times 30) \mathrm{mL}$ [6]. The shape of the curve was evaluated as bellshaped, tower, staccato, intermittent and plateau as recommended by the International Children's Continence Society ICCS [7, 8]. Pre-circumcision and post-circumcision uroflowmetry results were compared statistically.

\section{Statistical Analysis}

Data were evaluated using SPSS 13.0 program. A comparison of uroflow curves was carried out using the chi-square test. Wilcoxon test was used with the evaluation of uroflow parameters. A $p$-value of less than $<0.05$ was considered statistically significant.

\section{RESULTS}

The median age of 50 patients included in the study is 7 years (5-10 years). In the pre-circumcision uroflow examination, $35(70 \%)$ patients had a normal voiding curve, whereas a plateau voiding pattern was detected in $15(30 \%)$ patients. While the plateau voiding pattern continues in $4(8 \%)$ patients postcircumcision, the voiding pattern is normal in 46 $(92 \%)$ patients. The change of voiding pattern before and after circumcision is statistically significant $(p=$ $0.001)$.

Median flow time before circumcision is $16.34 \pm$ 1.43 seconds, and $15.36 \pm 1.65$ seconds after circumcision. The flow time is the same before and after circumcision $(p=0.24)$. The maximum flow rate median before circumcision is $14.36 \pm 1.65 \mathrm{~mL}$ (range: 9-28 mL) and $15.84 \pm 0.70 \mathrm{~mL}$ after circumcision. Maximum flow rate increased after

Table 1. Uroflowmetry parameters by precircumcision and postcircumcision

\begin{tabular}{lccc}
\hline Parameters & Pre-circumcision & Post-circumcision & $\boldsymbol{p}$ Value \\
\hline Voided volume (mL) & $175.5 \pm 96$ & $197.38 \pm 118$ & $\mathbf{0 . 0 3 1}$ \\
Qmax (mL/sec) & $14,36 \pm 1.65$ & $15,84 \pm 0.70$ & $\mathbf{0 . 0 1}$ \\
Qavg (mL/sec) & $10.96 \pm 0.42$ & $12.32 \pm 0.41$ & $\mathbf{0 . 0 1}$ \\
Time to Qmax (sec) & $15.87 \pm 0.71$ & $10.96 \pm 0.96$ & $\mathbf{0 . 0 0 2}$ \\
Flow time (sec) & $16.34 \pm 1.43$ & $15.36 \pm 1.65$ & 0.24 \\
\hline
\end{tabular}

Data are shown as mean \pm standard deviation. Bold marked data is statistically significant. Qmax $=$ maximum flow rate, Qavg = average flow rate 
circumcision $(p=0.01)$. The median time to maximum flow before circumcision is $15.87 \pm 0.71$ seconds, after which, this time is $10.96 \pm 0.96$ seconds. Time to maximum flow decreased after circumcision $(p=$ 0.002 ). The avarage flow rate before circumcision was $10.96 \pm 0.42$ seconds, after which, the avarage was $12.32 \pm 0.41$ seconds. An increase was detected in the avarage flow rate after circumcision $(p=0.01)$. The amount of voided volume was $175.5 \pm 96 \mathrm{cc}$ before circumcision, after which, this was measured as $197.38 \pm 118 \mathrm{cc}$. An increase was observed in the amount of voided volume after circumcision ( $p=$ $0.031)$. Uroflowmetry parameters by pre-circumcision and post-circumcision are shown in Table 1.

\section{DISCUSSION}

Circumcision is one of the most practiced surgical applications worldwide. Although it differs between societies, one in every 3 men worldwide is circumcised [9]. Bleeding and infection have been reported most frequently in several epidemiological studies evaluating post-circumcision complications [4]. The complication rate is determined by the expertise of the person who performed the circumcision and the environment in which the procedure was performed. Serious complications are not observed in sterile environments and in circumcisions performed by specialists [4, 10]. Although there are studies on surgical complications, no study evaluating the functional results of circumcision has been found. Uroflow is an easy-toapply, noninvasive method in which voiding is evaluated objectively. In our study, the functional results of circumcision were discussed by evaluating the pre-circumcision and post-circumcision uroflowmetry parameters.

Circumcision is performed for religious, cultural and medical reasons [4]. In all patients included in our study, circumcision was performed for religious and cultural reasons. There was no complaint to suggest voiding dysfunction in any of the patients. Although there were no complaints, $15(30 \%)$ patients had obstructive voiding pattern before circumcision. After circumcision, the obstructive voiding pattern was detected in $4(8 \%)$ patients. This result was interpreted to suggest that circumcision had a positive effect on urine flow. Since the obstructive pattern before circumcision is high, this suggests that prepuce can change the voiding pattern in children who do not have voiding problems. The significant improvement of the obstructive pattern after circumcision in the same children shows that circumcision has positive effects on urine flow. In a study conducted in healthy children in Spain, the bell-shaped curve, which is considered as the normal flow pattern, was seen in more than $90 \%$ of both genders [11]. In the same study, the plateau curve was observed in $5.2 \%$ in boys, but not in 9 to 14-year-old girls [11]. The anatomical difference of the urethra in men may be the cause of this obstructive pattern. In addition, no information was provided about whether the children with the obstructive pattern were circumcised or uncircumcised. In addition to urethral factors in the obstructive pattern in uroflow, the presence of preputium may contribute. It should also be remembered when making an assessment for voiding dysfunction that the foreskin may cause this pattern in children with obstructive voiding patterns. Clinical guidance should not be provided by evaluating the curve alone.

When uroflow parameters were compared in our study, the maximum flow rate, avarage flow rate and the time to maximum flow rate were found different. These results support the positive effects of circumcision on uroflow and voiding. In our study, post-circumcision uroflow assessment was performed in the early postoperative period. Late-term control uroflow assessments will allow for the comparison of the effects of circumcision on long-term uroflow.

Voiding problems and obstructive patterns observed after circumcision, which were not present before circumcision, are mostly related to meatal stenosis. In our study, there was no voiding problem in the first month after the circumcision evaluation. Meatal stenosis has also not been detected. All circumcisions were performed by a specialist in a sterile operating room environment under general anesthesia. Meatal stenosis is more commonly observed in circumcisions performed during the newborn and infant period [12, 13]. The children included in our study are children over 5 years old. The prediction that performing circumcision under suitable conditions and age range may prevent the development of meatal stenosis was also supported by this study. 


\section{CONCLUSION}

Circumcision has positive effects on uroflow parameters and voiding. Circumcision performed by specialists in the appropriate age range in sterile environments has positive results in terms of voiding physiology.

\section{Authors' contributions}

SS = Design of research, data collection and analysis, preparation of article and revisions; EAKE $=$ Data analysis, preparation of article and revisions .

\section{Conflict of interest}

The authors disclosed no conflict of interest during the preparation or publication of this manuscript.

\section{Financing}

The authors disclosed that they did not receive any grant during conduction or writing of this study.

\section{REFERENCES}

1. WHO/UNAIDS: New data on male circumcision and HIV prevention: Policy and programme implications: conclusions and recommendations. UNAIDS 2007.

2. Gray RH, Kigozi G, Serwadda D, Makumbi F, Watya S, Nalugoda F, et al. Male circumcision for HIV prevention in men in Rakai, Uganda: a randomised trial. Lancet 2007;369:657-66.

3. Bailey RC, Moses S, Parker CB, Agot K, Maclean I, Krieger
$\mathrm{JN}$, et al. Male circumcision for HIV prevention in young men in Kisumu, Kenya: a randomised controlled trial. Lancet 2007;369:643-56.

4. Weiss HA, Larke N, Halperin D, Schenker I. Complications of circumcision in male neonates, infants and children: a systematic review. BMC Urol 2010;10:2.

5. Nørgaard JP, Van Gool JD, Hjälmås K, Djurhuus JC, Hellström AL. Standardization and definitions in lower urinary tract dysfunction in children. Br J Urol 1998;81 Suppl 3:1-16.

6. Hjälmås K. Urodynamics in normal infants and children. Scand J Urol Nephrol Suppl 1988;114:20-7.

7. Nevéus T, von Gontard A, Hoebeke P, Hjälmås K, Bauer S, Bower W, et al. The standardization of terminology of lower urinary tract function in children and adolescents: report from the Standardisation Committee of the International Children's Continence Society. J Urol 2006;176:314-24.

8. Austin PF, Bauer SB, Bower W, Chase J, Franco I, Hoebeke P, et al. The standardization of terminology of lower urinary tract function in children and adolescents: update report from the Standardization Committee of the International Children's Continence Society. Neurourol Urodyn 2016;35:471-81.

9. WHO/UNAIDS: Male circumcision: global trends and determinants of prevalence, safety and acceptability. World Health Organization 2008.

10. Osuigwe A, Ikechebelu J, Okafor P: Circumcision-related complications in the male: experience amongst the Igbo's of Southeast Nigeria. Afr J Urol 2004;10:246-51.

11. Segura CG. Urine flow in childhood: a study of flow chart parameters based on 1,361 uroflowmetry tests. J Urol 1997; 157:1426-8.

12. Joudi M, Fathi M, Hiradfar M. Incidence of asymptomatic meatal stenosis in children following neonatal circumcision. J Pediatr Urol 2011;7:526-8.

13. Van Howe RS. Incidence of meatal stenosis following neonatal circumcision in a primary care setting. Clin Pediatr (Phila.) 2006;45:49-54 